\title{
电力系统安全管理刍议
}

\section{吴 楠}

国网内蒙古东部电力有限公司翁牛特旗供电分公司 内蒙古翁牛特旗 024500

DOI 号:10.18686/bd.v1i4.353

[摘要] 电力系统安全是电力企业最重要的课题。近来, 由于各种电网事故的发生, 不仅给电力企业造成了很大的损失, 对于人民的生活和安全也造成了严重的后果, 因此电力系统安全性的提高是一件亟待解决的问题。

[关键词］电力系统; 安全管理

\section{1、电力系统安全生产的重要性}

电力系统安全生产在社会经济发展和保证民生等方面 具有重要的作用。一方面, 电力系统生产具有高度自动化的 特点, 主要是由用电设备、变配电设施、输电线路以及发电 厂等组成电力网络, 互相制约也互相牵连, 这样才构成了一 个电力系统。在整个电力系统运行过程中电力的用电、供电 和发电是同时进行的, 所以要保证电力系统运行的稳定性 就必须保证供电发电和用电之间的平衡, 任何一个环节出 现问题如果不及时排除都会引发电力安全事故。现在我国 电力工业已经开始步人以“高度自动化、高电压、高参数、大 电网、大电厂、大机组”为特点的发展新阶段, 在促进电力行 业发展的同时也给电力系统安全生产提出了更高的要求。 另一方面, 电力系统在生产过程中具有特种作业多、高速旋 转机械多、易燃易爆和有毒材料多、高压高温设备多等特 点, 这些特点决定了电力生产是一项非常危险的工作, 稍有 不慎就会有电力安全事故发生, 而且一般都危及生产人员 的生命, 所以在电力系统生产中必须重视生产的安全性; 电 力企业必须保障电力职员的自身的安全。

\section{2、电力系统安全问题分析}

2.1、变电系统运行中的安全问题

在变电系统的运行过程中, 多种电气设备会随着使用 时间的增加而呈现出不同程度的老化、破损以及短路等问 题, 在实际的运行过程中如果不能及时的进行维护、修补以 及更新等, 将使得整个电力系统不能安全运行。但是, 因为 这部分电气设备安全问题的发生是随机的, 而针对变电系 统的运行问题维护则是定期进行的, 甚至部分运行人员只 是在上级安排检查之后才进行, 根本不能及时的发现、识别 相关的安全隐患, 导致对应的安全检查工作存在安全隐患, 使得整个系统的安全运行受到影响。

\section{2、安全管理体系叒待完善}

通过对当前大量的电力系统安全事故进行分析、总结 和统计之后, 发现导致变电运行事故的主要原因是安全管 理体制不够完善,管理工作不到位而造成的。当前, 我国大 部分的电力企业为了提高电力系统的运行可靠性, 而将大 量的人力和资金放在设备、技术的更新方面,这确实在一定
程度上提高了电力系统的运行效率, 也很大程度上确保了 电力系统的运行可靠性。但是, 部分人员错误的认为先进技 术和设备的应用就能够保证系统完全稳定运行, 从而忽视 了认为管理工作在安全管理中的作用, 这也是电力系统运 行过程中安全管理体系亟待完善的一个重要问题。

\section{3 、习惯性违章现象的存在}

电力系统运行过程中的习惯性违章就是指在安全生产 过程中存在着一些习以为常的违章操作行为。其主要包括 违章指挥、违章操作、违反劳动纪律等。其中, 典型的违章操 作行为是无票作业, 对一些临时性的作业工作, 尤其是配电 修理等工作中容易出现无票作业问题。例如, 某配电作业人 员，在没有完成修理票的填写工作时就开始进行修理作业 工作, 最终导致了一起触电事故。这些不正确的违章作业方 式给电力系统的安全运行带来了一定的隐患, 不能保证电 力系统的安全运行。

\section{4、安全器具管理混乱}

这方面的问题主要表现在这样几个方面:其一,部分基 层供电单位在供电营业所进行登高作业过程中使用的作业 工具以及小型的起降设备的质量管理及维护工作不合格, 导致设备不能正常使用, 或者是在使用中容易出现安全事 故; 其二, 缺乏对安全器具的定期检查意识,设备的报废处 理流程流于形式,一些已经明显超期的设备还在超期使用。

\section{3、电力系统安全生产管理的解决措施}

3.1 、树立 “安全第一, 预防为主, 综合治理” 的科学理 念,强化安全意识

安全生产最根本、最首要的要素是人, 人是安全生产好 快的关键, 也是安全生产过程中最活跃的因素。据统计, $90 \%$ 以上的安全事故主要来自人为原因, 因此, 加强人的安 全意识迫在眉眏。一方面要加强员工安全思想教育。安全生 产过程中, 电力员工所经历的经验教训是教育的生动材料, 可以有效提高员工的安全知识水平,增强安全意识。另一方 面要建立和完善激励机制。在满足员工的基本需求后,社会 需求和自我受尊重的需求更加得到关注。员工需要从集体 活动及社交活动中寻求机会, 在不同的团体内展现自己的 特长, 这样才能促使基层员工能够相互得到关注和尊重。 
3.2 、坚持系统长效安全管理机制, 提高企业整体管理 水平

首先, 根据电力生产经营和管理工作的实践情况, 推行 精细化管理, 不断修订和调整电力工业相关的法律法规、标 准以及办法和措施。其次, 落实岗位安全责任制。电力工业 的安全生产目标应切实分解到各级员工, 加强现场安全监 督检查, 即时发现并消除现场存在的潜在隐患, 制定切实可 行的班组轮靠考核奖惩制度并严格执行, 考核与制度挂钩, 做到规范化管理。同时, 在奖惩制度上, 改善员工生活, 提高 第一生产线上安全生产的补贴, 做到“谁主管, 谁负责, 谁在 岗, 谁负责”, 从安全思想上做到由强制性到自觉性的质的 飞跃。最后, 企业要公开选拔人才, 创新人力资源管理, 引进 专业技术人才, 拓宽人才的发展空间, 增强企业的整体执行 力, 确保安全指令畅通下达到各级员工。

3.3 、革新电力系统设备技术, 降低电力安全生产事故 的发生

电力工业的发展离不开科技的进步, 只有不断的创新, 才能实现快速发展。电力工业需要根据我国的实际情况出 发, 不断发挥科学技术, 吸收国内外已有的先进技术和管理 经验, 才能促进电力工业发展过程中的整体优势。一方面要 全面探索电力设备整修的实现方案, 加大科技投资力度, 整 合科研资源, 积极筹建电网诊断中心, 加快电网自动化、智 能化建设。另一方面, 加快建设以信息库及离线检测为主,
设备状态信息和历史信息库、离线检测库、在线检测库“三 库合一”为辅的新型检测模式, 为提高坚实的供电网络提供 强有力的技术支持。同时, 加快科研成果的转化, 提升电网 安全稳定水平、电力设备的健康水平和运行管理水平, 降低 电网损耗, 促进节能环保的和谐型社会建设。

3.4、提高安全器具的质量管理水平

首先要严格管理施工及维修器具, 对于到期、损坏的器 具要进行严格检查, 发现不合格而不能继续使用的器具要 坚决予以报废。对于通过修缮还能够使用的器具要及时的 进行修理, 在修理完成之前坚决不进入器具使用存放仓库。 其次, 还应该对外包施工队伍的安全施工规范等进行审查。 尤其是发包单位和监理单位, 应该对之进行安全检查和监 督, 通过落实安全器具检修管理制度的方式保证工具、器具 等处于最佳的使用状态。

\section{参考文献}

[1]苗培仁.电力安全管理, 中国电力出版社, 2007。

[2]任国明, 邵玉槐. 电力企业安全生产形势及问题探 讨[J]中国安全生产科学技术, 2007,3.

[3]安徽省电力培训中心.电力企业班组管理案例及评 析.中国水利水电出版社, 2008 .

[4]李西泉, 陈辉华. 电力系统安全稳定运行基本要求 的探析[J]. 华中电力.2004(02). 